\title{
Eventración diafragmática izquierda en un adulto con síntomas de fallo cardíaco derecho: reporte de un caso raro
}

\author{
Roger Malo-Barres' ${ }^{1}$, Xavier Herranz ${ }^{1}$, José Antonio Maestre ${ }^{2}$, Miguel Ángel Carrasco ${ }^{3}$, Anna Rossell-Casal ${ }^{4}$ \\ 'Servicio de Medicina Interna. Hospital Universitari General de Catalunya. Sant Cugat del Vallès (Barcelona). España \\ ${ }^{2}$ Servicio de Cirugía Torácica. Hospital Universitari General de Catalunya. Sant Cugat del Vallès (Barcelona). España \\ ${ }^{3}$ Servicio de Anatomía Patológica. Hospital Universitari General de Catalunya. Sant Cugat del Vallès (Barcelona). España \\ ${ }^{4}$ Universitat Internacional de Catalunya. Hospital Universitari General de Catalunya. Sant Cugat del Vallès (Barcelona). España
}

Recibido: 18/03/2019

Aceptado: 01/04/2019

En línea: 30/04/2019

Citar como: Malo-Barres R, Herranz X, Maestre JA, Carrasco MA, Rossell-Casal A. Eventración diafragmática izquierda en un adulto con síntomas de fallo cardíaco derecho: reporte de un caso raro. Rev Esp Casos Clin Med Intern (RECCMI). 2019 (Abr); 4(1): 30-32. doi: 10.32818/reccmi.a4n1a11.

Autor para correspondencia: Anna Rossell-Casal. anna.rossell@uic.es

\section{Palabras clave \\ $\triangleright$ Eventración diafragmática \\ $\triangleright$ Insuficiencia cardíaca derecha \\ $\triangleright$ Hernia diafragmática}

\section{Keywords}

$\triangleright$ Diaphragmatic eventration

$\triangleright$ Right-sided heart failure

$\triangleright$ Diaphragmatic hernia

\begin{abstract}
Resumen
La eventración diafragmática es una anomalía congénita o adquirida en la cual las fibras musculares son reemplazadas por tejido fibroso, produciéndose una disminución de la capacidad contráctil del diafragma y el consiguiente prolapso de las estructuras abdominales hacia la cavidad torácica. La mayoría de los casos en adultos son asintomáticos, y la disnea y la ortopnea son las manifestaciones más habituales. Presentamos el primer caso de un varón de 56 años que acudió a Urgencias por edemas en extremidades inferiores y escroto como primera manifestación de una eventración diafragmática izquierda.
\end{abstract}

Abstract
The diaphragmatic eventration is a congenital anomaly in which the muscular fibres are replaced by fibrous
tissue causing a reduction of the contractile capacity of the diaphragm and the prolapse of abdominal struc-
tures in the thoracic cavity. The majority of the cases are asymptomatic but when present, the symptoms are
dyspnoea or orthopnoea. We report the first case of a 56 years old man who turned up in the Emergency room
presenting edema in lower extremities and scrotum as the first clinical manifestation of a left diaphragmatic
eventration.

\section{Puntos destacados}

$\triangleright$ La eventración diafragmática izquierda no suele dar síntomas en el adulto, pero puede manifestarse en forma de edemas periféricos secundarios al desplazamiento de las estructuras mediastínicas.

$\triangleright$ El diagnóstico definitivo suele ser quirúrgico.

\section{Introducción}

La eventración del diafragma (ED) estrictamente se define como un defecto congénito parcial o completo en el desarrollo de la porción muscular del diafragma que normalmente se encuentra en la infancia y produce insuficiencia respiratoria. En ocasiones, la ED es adquirida por una parálisis frénica, a menudo idiopática, que produce la denervación progresiva de las fibras musculares diafragmáticas ${ }^{1}$, la elevación anormal y permanente del diafragma, y el consiguiente prolapso de estructuras abdominales y compresión de estructuras torácicas ${ }^{2}$.
La primera descripción de esta anomalía fue realizada por Petit en 1790, quien la describió como una forma especial de hernia diafragmática "sin ninguna separación muscular de las fibras tendinosas del diafragma"3. A diferencia de la hernia diafragmática, en la eventración no se produce una disrupción entre el diafragma y los márgenes costales.

La ED es una patología que rara vez produce síntomas en el adulto y su hallazgo, la mayor parte de las veces, es casual en el proceso diagnóstico de otra patología. En caso de manifestarse lo suele hacer en forma de palpitaciones, disnea, ortopnea, neumonías de repetición o síntomas gastrointestinales como dispepsia, epigastralgia o distensión abdominal ${ }^{4}$. El tratamiento suele ser conservador y únicamente existe indicación quirúrgica cuando el paciente se encuentra sintomático 5 .

Se han descrito en la literatura muy pocos casos de ED que produzcan síntomas debido a la compresión de estructuras cardiovasculares, todos ellos producidos por elevación del diafragma derecho y la consiguiente com- 
presión hepática de la aurícula derecha ${ }^{6}$. Presentamos el primer caso de ED izquierda en adultos con edemas periféricos como forma de presentación clínica.

\section{Historia clínica: antecedentes, enfermedad actual, exploración física}

Varón de 56 años de edad que consultó al Servicio de Urgencias por edemas de miembros inferiores y escroto de 10 días de evolución. El paciente no tenía antecedentes patológicos destacables ni refería cirugías previas o traumatismos torácicos o abdominales. A la exploración física destacó hipofonesis en hemitórax izquierdo y desplazamiento de los tonos cardíacos a hemitórax derecho.

\section{Pruebas complementarias}

Se efectuaron las siguientes pruebas:

- Analítica. Hemoglobina 9,2 g/dl (13-17), hematocrito 29\% (39-52), VCM 86 f (80-100), HCM 27 pg (27-32). Leucocitos, plaquetas, función renal y hepática sin alteraciones. NT-proBNP 2.210 ng/l (50-75 años, > 900 ng/l probable)

- Electrocardiograma. Ritmo sinusal a 65 lpm, normal.

- Radiografía de tórax. Elevación del hemidiafragma izquierdo con shift mediastínico contralateral derecho y presencia de asas intestinales en el hemitórax izquierdo (Figura 1).

- Tomografía axial computarizada (TAC) torácica sin contraste intravenoso. Elevación diafragmática izquierda con ascenso del contenido abdominal hasta altura carinal, desplazando estructuras mediastinales a la derecha y colapsando de forma pasiva parte del pulmón izquierdo (Figura 2).

- Ecocardiograma transtorácico. Ventrículo izquierdo no dilatado con ligera hipertrofia septal y contractilidad global conservada junto con fracción de eyección preservada. El ventrículo derecho no se encontró dilatado y su dinámica global era correcta. El tiempo de aceleración pulmonar (177 ms) era normal, lo que permitió descartar un incremento de las resistencias vasculares pulmonares. Tampoco se evidenció derrame pericárdico. Sin embargo, el estudio se vio limitado por una ventana acústica subóptima, lo que no permitió valorar de forma adecuada la vena cava inferior.

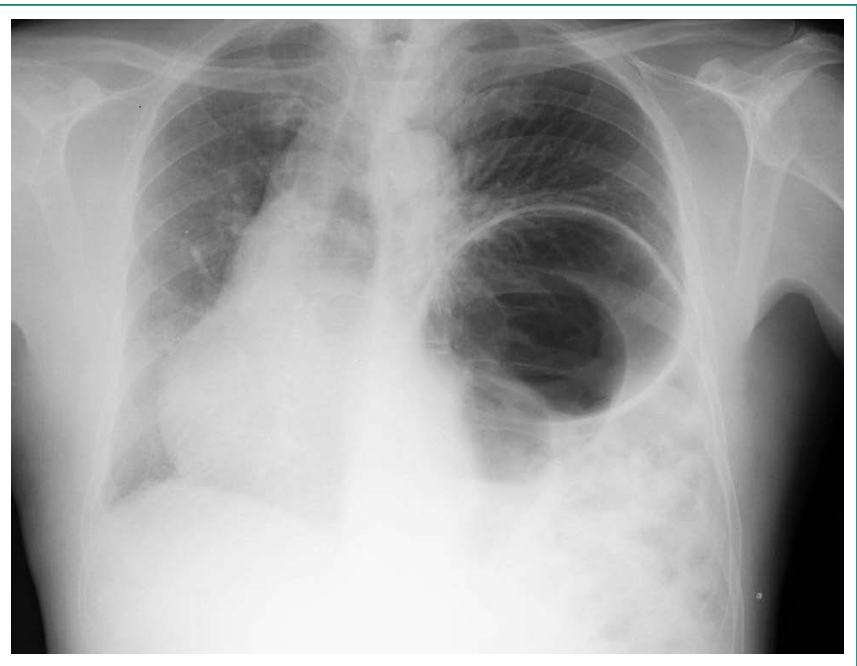

Figura 1. Radiografía de tórax en la que se evidencian elevación del hemidiafragma izquierdo con shift mediastínico contralateral derecho y presencia de asas intestinales en el hemitórax izquierdo

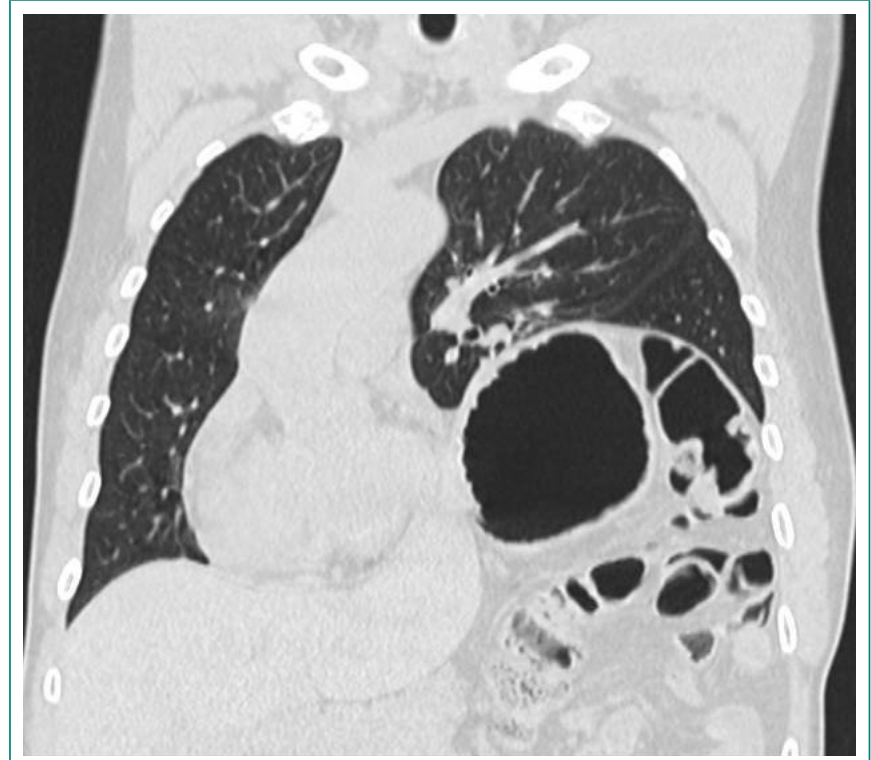

Figura 2. Corte coronal de TAC que muestra la presencia de contenido abdominal en la cavidad torácica y el desplazamiento del mediastino a la derecha

\section{Evolución}

Ante la sospecha de insuficiencia cardíaca derecha, se inició tratamiento con diuréticos de asa, con resolución de los edemas a los 3 días.

Valorado por Cirugía Torácica, y de forma electiva, se realizó toracotomía posterolateral izquierda con plicatura del diafragma y colocación de una malla Marlex ${ }^{\circledast}$. En la operación se observó un diafragma delgado y membranoso con eventración total y desplazamiento del estómago y asas intestinales de su posición normal.

La biopsia del diafragma mostró una pared fibroadiposa con un leve infiltrado inflamatorio perivascular de tipo crónico compatible con una eventración diafragmática (Figura 3).

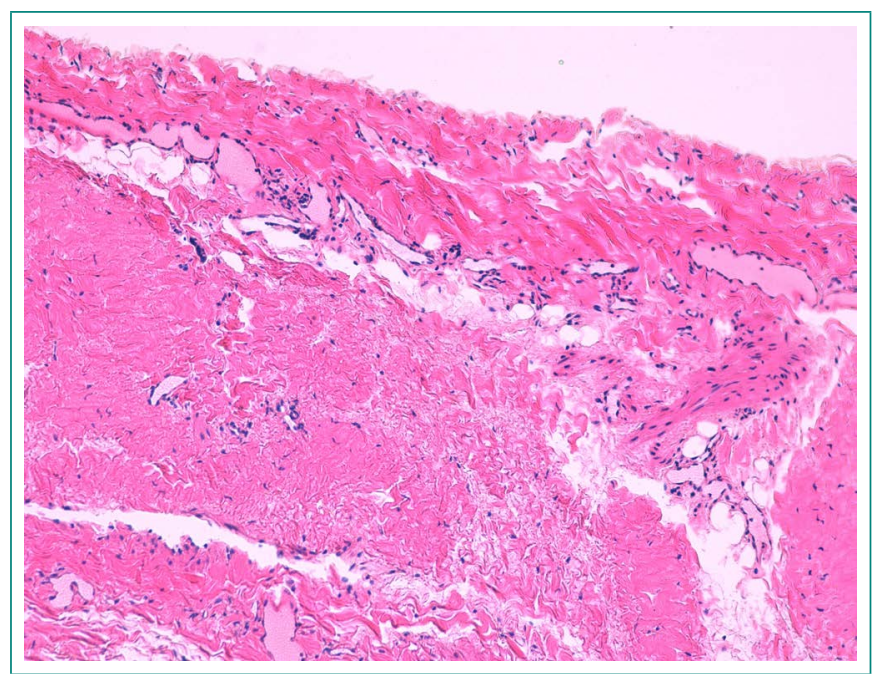

Figura 3. Imagen microscópica a 10x del diafragma que muestra pared fibroadiposa con leve infiltrado inflamatorio perivascular de tipo crónico 
La Figura 4 muestra la radiografía de tórax realizada 6 días después de la plicatura diafragmática donde se evidencia una restitución de la anatomía.

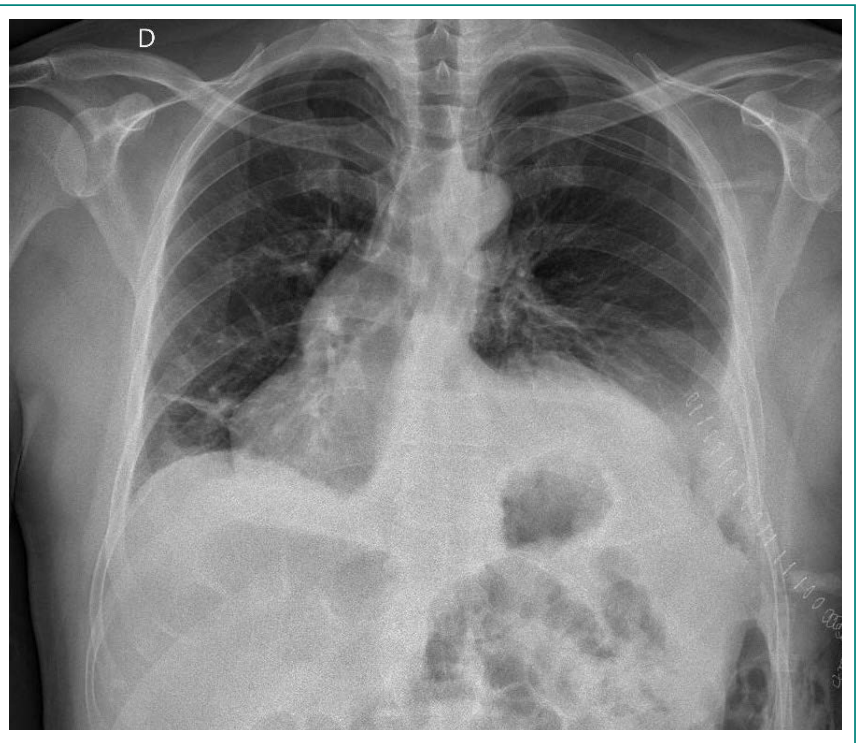

Figura 4. Radiografía de tórax realizada 6 días después de la plicatura del diafragma donde se evidencia restitución de la anatomía

\section{Diagnóstico principal}

Edemas maleolares secundarios a eventración diafragmática izquierda.

\section{Discusión y conclusiones}

La eventración diafragmática es una elevación anormal de una hoja diafragmática, debida a una atrofia de las fibras musculares. Suele ser congénita, si bien también puede ser secundaria a cambios degenerativos por lesión del nervio frénico. La TAC permite orientar el diagnóstico y excluir una causa secundaria de parálisis frénica. Nuestro paciente no reportaba historia previa de cirugía torácica, traumatismos, infecciones o patología cervical. La principal entidad dentro del diagnóstico diferencial de la ED es la hernia diafragmática. La hernia se define como el prolapso anormal de un órgano o de otra estructura corporal a través de un orificio natural en una cubierta, membrana o músculo o hueso ${ }^{7}$.
La eventración diafragmática se diferencia de la hernia por presentar continuidad y adhesión a los márgenes costales. La presentación clínica y las imágenes radiográficas de la ED son muy similares a las de la hernia diafragmática, por lo que diferenciarlas supone un reto diagnóstico y a menudo el diagnóstico definitivo es quirúrgico.

Por otra parte, la eventración completa del diafragma es casi exclusiva del hemidiafragma izquierdo y se observa más frecuentemente en hombres ${ }^{8}$, como es el caso de nuestro paciente. La atrofia de las fibras musculares diafragmáticas produce la eventración de las vísceras abdominales junto con los órganos abdominales. La mayor parte de los casos pasan desapercibidos y su hallazgo es incidental. Sin embargo, la compresión de las estructuras torácicas puede manifestarse en forma de disnea, palpitaciones, dolor torácico o síntomas gastrointestinales.

No hemos encontrado ningún caso descrito en la literatura de edemas periféricos como primera manifestación de una eventración diafragmática, probablemente por compresión de la vena cava inferior. La mala ventana acústica del ecocardiograma en nuestro paciente $y$, posiblemente, haber realizado dicha prueba tras varios días de tratamiento depletivo, no permitieron objetivar la congestión de la vena cava inferior como mecanismo fisiopatológico más plausible de los edemas.

\section{Bibliografía}

1. Maish MS. The diaphragm. Surg Clin North Am. 2010 Oct; 90(5): 955-968. doi: 10.1016/j.suc.2010.07.005.

2. León-Atance P, Martínez-Hernández NJ, Milla-Saba AM, Roca-Fernández J. Patología del diafragma. Arch Bronconeumol. 2011; 47(8): 37-40. doi: 10.1016/S0300-2896(11)70066-7.

3. París F, Blasco E, Cantó A, Tarazona V, Casillas M. Diaphragmatic eventration in infants. Thorax. 1973 Jan; 28(1): 66-72.

4. Groth SS, Andrade RS. Diaphragmatic eventration. Thorac Sur Clin. 2009 Nov; 19(4): 511-519. doi: 10.1016/j.thorsurg.2009.08.003.

5. Mouroux J, Venissac N, Leo F, Alifano Marco, Guillot François. Surgical treatment of diaphragmatic eventration using video-assisted thoracic surgery: a prospective study. Ann Thorac Surg. 2005 Jan; 79(1): 308-312. doi: 10.1016/j.athoracsur.2004.06.050.

6. Lau-Gary TE, To-Andrew CY. Eventration of the right hemidiaphragm with resultant right atrial compression: a rare finding. Echocardiography. 2016; 33(9): 1432-1433. Disponible en: https://doi.org/10.1111/echo.13268

7. Dorland. Diccionario Enciclopédico Ilustrado de Medicina. 30th ed. Madrid. Elsevier, 2005.

8. Christensen P. Eventration of the diaphragm. Thorax. 1959; 14: 311-319. 